\title{
Kajian Implementasi Alokasi Frekuensi Komunikasi untuk Pelayaran Rakyat di Indonesia
}

\author{
TENGKU AHMAD RIZA
}

\author{
D3 Teknik Telekomunikasi Fakultas Ilmu Terapan Universitas Telkom \\ Email : tengkuriza@telkomuniversity.ac.id
}

\begin{abstract}
ABSTRAK
Pada saat ini pelayaran di Indonesia melakukan komunikasi antar nelayan pada pelayaran rakyat menggunakan frekuensi yang tidak resmi dengan alasan perangkat komunikasi lebih murah dan mudah didapat. Dalam penelitian ini dilakukan kajian implementasi alokasi spektrum frekuensi yang digunakan khusus untuk pelayaran rakyat di Indonesia. Alokasi spektrum frekuensi ini dapat digunakan oleh nelayan untuk melakukan komunikasi antar nelayan dengan menggunakan frekuensi yang resmi. Dimana untuk menetapkan frekuensi digunakan dengan melakukan studi literatur. Hasil kesimpulan yang diperoleh adalah untuk komunikasi antar nelayan dari satu kapal ke kapal lainnya dapat menggunakan frekuensi VHF (Very High Frequency) 30 - $300 \mathrm{MHz}$ dengan pertimbangan jarak jangkauan. Frekuensi yang dimungkinkan untuk digunakan oleh pelayaran rakyat adalah $2170-2173,5 \mathrm{KHz}, 2190-2194 \mathrm{KHz}, 8100-8195 \mathrm{KHz}$, $18780-18900 \mathrm{KHz}, 25070-25210 \mathrm{KHz}, 159.05 \mathrm{MHz}, 159.075 \mathrm{MHz}$ dan 172-173 $\mathrm{MHz}$.
\end{abstract}

Kata kunci: Spektrum Frekuensi, Pelayaran Rakyat, Perangkat Komunikasi, Komunikasi, nelayan

\begin{abstract}
At this time a cruise in Indonesia communication between fishermen on the cruise people using unofficial frequencies by reason of communication devices are cheaper and accessible. In this research, the study of the allocation of the frequency spectrum used specifically for cruise people in Indonesia. The allocation of the frequency spectrum can be used by fishermen for communication between fishermen using official frequency. Where to set the frequency used by the study of literature. The conclusion obtained for communication between fishermen from one ship to another fist using VHF frequencies (Very High Frequency) 30-300 $\mathrm{MHz}$ frequency range and distance considerations in the possible to be used by the cruise people are from 2170 to $2173.5 \mathrm{KHz}, 2190-2194 \mathrm{kHz}, 8100-8195 \mathrm{kHz}, 18780-18900 \mathrm{kHz}, 25070-25210$ $\mathrm{kHz}, 159.05 \mathrm{MHz}, 159075 \mathrm{MHz}$ and $172-173 \mathrm{MHz}$
\end{abstract}

Keywords: Frequency Spectrum, Civil marine, Communication Peripheral, Communication, Fisherman. 


\section{PENDAhUlUAN}

Negara Republik Indonesia mempunyai kondisi geografis yang unik dan sangat luas kurang lebih terdiri dari ribuan pulau yang di kelilingi lautan dengan kondisi demografi yang sangat tersebar dan konsentrasi penduduk di beberapa pulau-pulau tertentu, antara lain di pulau Jawa, Bali, Sumatera dan beberapa pulau lainnya secara tidak merata. Mengingat kondisi geographis dan demografis seperti tersebut maka salah satu alat pemersatu bangsa yang sangat potensial di Indonesia adalah terselenggaranya telekomunikasi secara baik, terjangkau oleh masyarakat luas dan dengan cakupan yang optimal di seluruh pelosok wilayah Indonesia dan juga.

Beberapa frekuensi berkaitan dengan keselamatan jiwa manusia, diantaranya adalah frekuensi Maritim. Kebutuhan frekuensi maritim semakin banyak sesuai dengan banyaknya pembangunan pelabuhan yang di tiap Negara. Kebutuhan akan alokasi frekuensi maritim bagi Indonesia sangat penting, lokasi Indonesia yang strategis, diapit oleh benua Australia, asia dan amerika, serta diantara samudra hindia dan pacific menjadikan Indonesia satusatunya Negara yang paling berpotensi menjadi Negara transit bagi kapal laut, selain kapalkapal besar Indonesia juga mempunyai kapal-kapal kecil di bawah 300 GT (Gross Ton) yang disebut sebagai kapal nelayan atau yang lebih dikenal dengan sebutan pelayaran rakyat. Pelayaran rakyat merupakan kegiatan di lautan yang dilakukan oleh nelayan tradisional dengan menggunakan kapal kayu yang dibuat dengan teknologi tradisional, sehingga mempunyai jangkauan operasi dan kemampuan teknisnya yang relatif terbatas.

Sementara itu spektrum frekuensi radio merupakan sumber daya alam yang terbatas yang mempunyai nilai strategis dalam penyelenggaraan telekomunikasi dan dikuasai oleh negara. Pemanfaatan spektrum frekuensi radio sebagai sumber daya alam tersebut perlu dilakukan secara tertib, efisien dan sesuai dengan peruntukkannya sehingga tidak menimbulkan gangguan yang merugikan.

Penelitian ini fokus dan bertujuan untuk memberikan kajian untuk mengimplementasikan alokasi frekuensi komunikasi yang dapat dipergunakan oleh para nelayan yang termasuk sebagai pelayaran rakyat di seluruh Indonesia. Sehingga para nelayan dapat mempergunakan frekuensi yang resmi.

\subsection{Spektrum Frekuensi Radio}

Spektrum Frekuensi merupakan istilah penamaan yang diberikan untuk mengukur jumlah atau panjang gelombang radio yang beredar dalam ukuran satu detik. Atau dengan kata lain frekuensi adalah banyaknya gelombang dalam satu detik (Yudhariksawan, 2005). Dan satuan ukuran yang digunakan adalah Hertz $(\mathrm{Hz})$. Kata Hertz diambil dari nama Heinrich Hertz, Ilmuwan Jerman yang pertama kali membuktikan Teori Gelombang Elektromagnetik.

Sementara pengertian Spektrum Frekuensi Radio adalah susunan pita frekuensi radio yang mempunyai frekuensi lebih kecil dari $3000 \mathrm{Ghz}$ sebagai satuan getaran gelombang terdapat dalam dirgantara (ruang udara dan antariksa). Alokasi Spektrum Frekuensi Radio Indonesia ditetapkan dengan mengacu kepada alokasi Spektrum Frekuensi Radio Internasional untuk wilayah 3 ( region 3 ) sesuai Peraturan Radio yang ditetapkan oleh Himpunan Telekomunikasi Internasional ( ITU ) ITU Radio Regulation 2012 dan Peraturan Menteri Komunikasi dan Informatika RI Nomor 25 Tahun 2014 Tentang Tabel Alokasi Spektrum Frekuensi Indonesia (Yudhariksawan, 2005). 


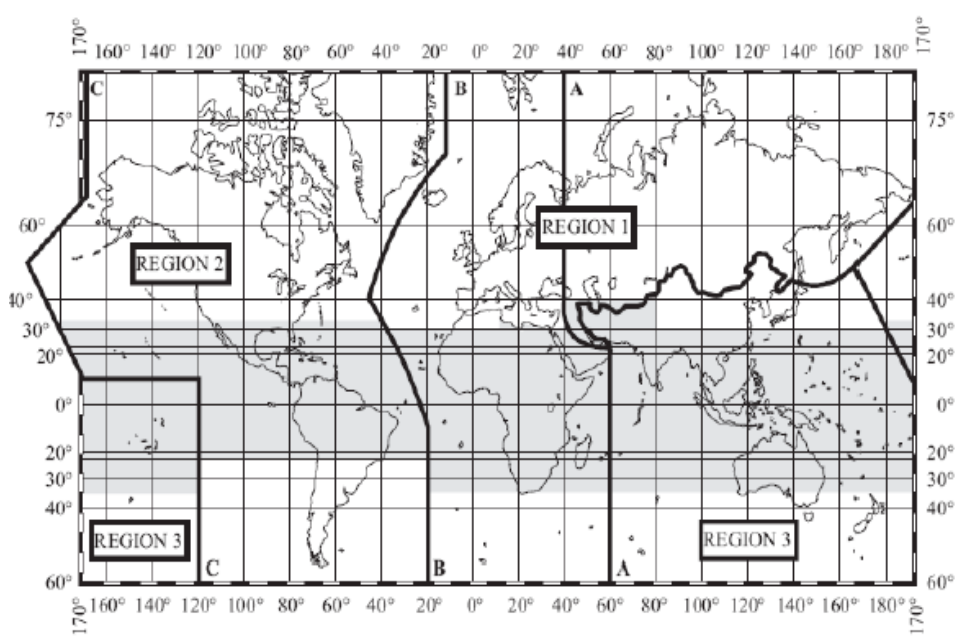

Gambar 1. Pembagian Region Dunia (ITU Regulation, 2012)

\subsection{Pelayaran Rakyat}

Indonesia merupakan salah satu negera kepualauan dengan jumlah pulau lebih kurang 17.480 pulau dengan dengan bentangan laut selaus 5,8 juta $\mathrm{km} 2$, sehingga Indonesia selain terkenal sebagai negara kepulauan juga negara maritim didunia.

Dalam Peraturan Pemerintah Nomor 20 Tahun 2010 sebagaimana diubah pada Peraturan Pemerintah 22 Tahun 2011 telah menyebutkan bahwa pelayaran rakyat adalah kegiatan angkutan laut yang ditujukan untuk mengangkut barang dan/atau hewan dengan menggunakan kapal layar, kapal layar motor tradisional dan kapal motor dengan ukuran tertentu (Peraturan Pemerintah Republik Indonesia Nomor 20, 2010).

Pelayaran rakyat merupakan kegiatan di lautan yang dilakukan oleh nelayan tradisional dengan menggunakan kapal kayu yang dibuat dengan teknologi tradisional, sehingga mempunyai jangkauan operasi dan kemampuan teknisnya yang relatif terbatas (Peraturan Pemerintah Republik Indonesia Nomor 20, 2010).

\subsection{Perangkat Komunikasi}

Definisi atau pengertian alat komunikasi adalah semua media yang digunakan untuk menyebarkan atau menyampaikan informasi, baik itu informasi kepada satu orang saja atau kepada banyak orang. Alat komunikasi ini juga bukan hanya menyampaikan informasi saja tetapi juga menghasilkan informasi.

Berdasarkan medium fisik yang digunakan, sistem komunikasi dapat dikelompokkan menjadi dua jenis yaitu sistem komunikasi kabel dan nirkabel. Fokus penelitian ini adalah sistem komunikasi nirkabel dengan menggunakan frekuensi radio atau gelombang radio sebagai medium pembawa informasi atau lebih dikenal dengan sistem komunikasi radio. Spektrum frekuensi radio adalah kumpulan pita frekuensi radio yang memiliki lebar tertentu. Undangundang penyiaran No. 32/2002 Pasal 1 Ayat 8 menyebutkan bahwa spektrum frekuensi radio merupakan gelombang elektromagnetik yang merambat di udara serta ruang angkasa tanpa medium buatan dan tidak dapat dibuat atau didaur ulang oleh manusia (Presiden Republik Indonesia, 2002). Gelombang radio merupakan bagian dari gelombang elektromagnetik pada spektrum frekuensi radio dengan panjang gelombang lebih dari 10-3 meter dan berada pada daerah $\mathrm{MHz}$. Sistem komunikasi radio juga dapat diartikan sebagai sistem komunikasi yang 
tidak menggunakan kawat dalam proses perambatannya melainkan menggunakan udara atau ruang angkasa sebagai pengantar (Wahab, 2014).

Sistem komunikasi radio pada dasarnya terdiri dari 3 bagian yaitu pesawat radio, antena, dan power supply. Pesawat radio atau perangkat radio berdasarkan fungsinya terbagi menjadi bagian pemancar (transmitter) dan bagian penerima (receiver) yang menjadi satu kesatuan transceiver(Wahab, 2014).

Penggunaan sistem komunikasi nirkabel untuk band frekuensi maritim mengalami perkembangan yang sangat pesat. Sistem komunikasi kapal digunakan untuk berhubungan antara awak kapal yang berada pada satu kapal, kapal lain, petugas darat, dan stakeholder lain yang terkait dengan aktivitas pelayaran. Baiknya sistem komunikasi yang terdapat pada kapal laut merupakan hal yang penting mengingat angka kecelakaan transportasi di laut Indonesia cukup tinggi disebabkan oleh buruknya sistem komunikasi yang terdapat di kapal (Wahab, 2014).

\section{METODOLOGI PENELITIAN}

Dalam Penelitian ini menggunakan metode sebagai berikut:

1. Studi literatur.

Mempelajari teori - teori yang dibutuhkan dalam pengerjaan penelitian melalui berbagaii referensi baik buku-buku maupun jurnal - jurnal yang terkait dan juga melakukan mempelajari aturan-aturan baik Internasional maupun nasional mengenai pelayaran.

2. Studi Banding (Benchmark).

Melakukan studi banding (Benchmark) terhadap negara-negara lain di dunia mengenai pelayaran rakyat terutama terhadap negara yang banyak nelayan atau pelayaran rakyat.

3. Pengolahan Data dan Analisis

Melakukan pengolahan data terhadap frekuensi eksisting, data hasil studi banding (Benchmark) dan kemungkinan frekuensi lainnya terhadap aturan yang ada baik skala aturan nasional maupun aturan Internasional

4. Rekomendasi

Memberikan rekomendasi dan kesimpulan penggunaan frekuensi khusus untuk digunakan pada pelayaran rakyat di Indonesia. 


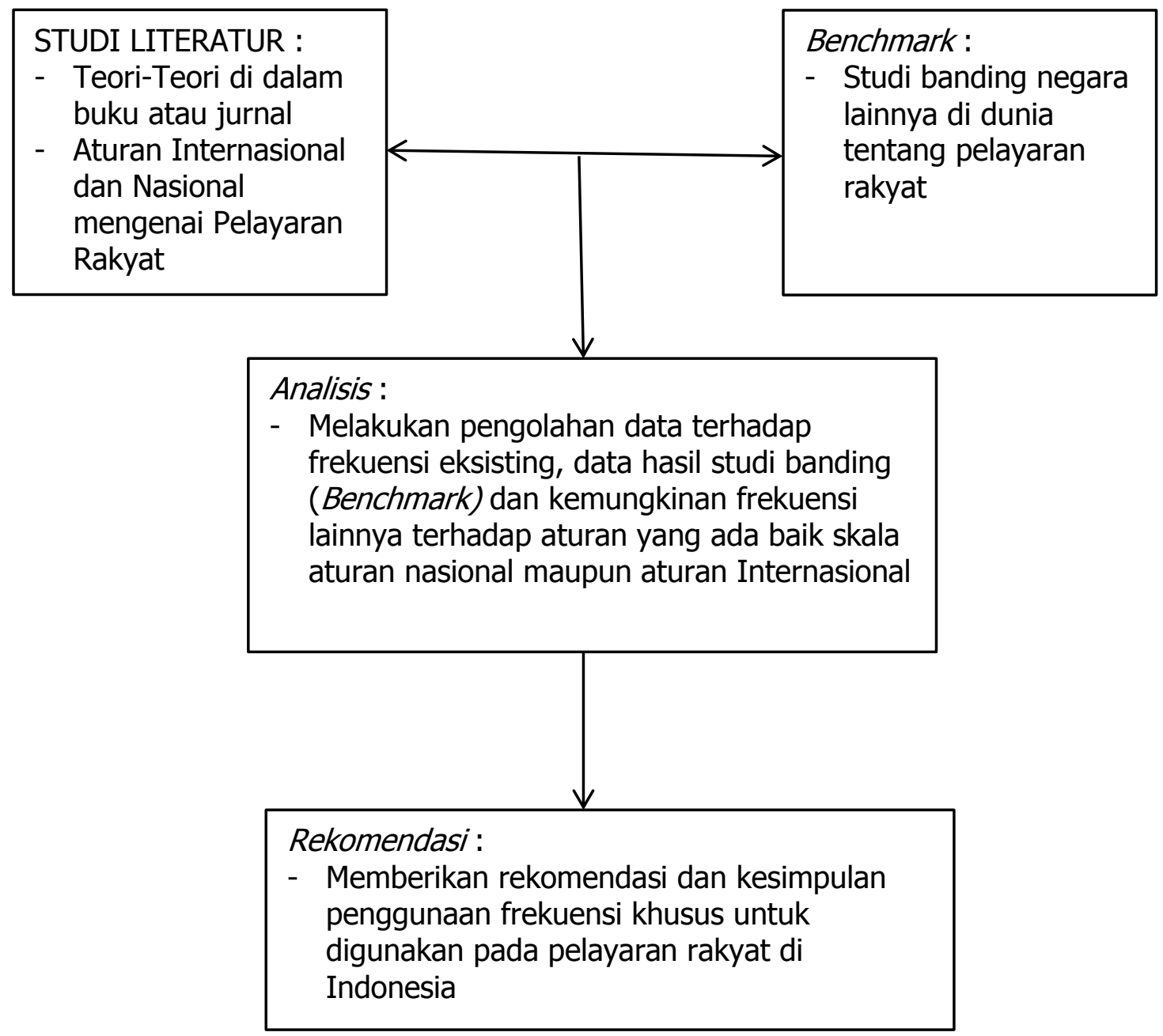

Gambar 2. Metodologi Penelitian

\section{HASIL DAN PEMBAHASAN}

\subsection{Identifikasi Permasalahan}

Sistem navigasi dan komunikasi untuk aktivitas bergerak idealnya menggunakan alat atau perangkat nirkabel dengan spektrum frekuensi radio sebagai mediumnya. Pelayaran telah menggunakan berbagai jenis alat dan perangkat telekomunikasi dalam sistem navigasi dan komunikasi dengan frekuensi radio sebagai mediumnya di antaranya (Wahab, 2014) :

\section{Handphone}

Handphone sebagai salah satu alat komunikasi yang banyak beredar di masyarakat mengusung fleksibilitas sebagai salah satu keunggulannya. Menggunakan handphone untuk menghubungi nahkoda atau awak kapal.

\section{Handy Talky}

Kapal lumba-lumba biasanya menggunakan alat komunikasi handy talky $(\mathrm{HT})$ yang bekerja pada frekuensi Very High Frequency (VHF). HT dengan frekuensi kerja VHF juga digunakan salah satu pemilik kapal perseorangan sehingga biasanya komunikasi hanya terjadi antara 
kedua pihak tersebut. Petugas di kantor syahbandar juga menggunakan HT pada frekuensi level High Frequency (HF) untuk memandu kedatangan dan keberangkatan kapal.

\section{High Frequency Tranceiver}

Komunikasi Menggunakan HF tranceiver pada frekuensi 9.932.5 MHz Mode Upper Side Band (USB). Perangkat ini digunakan untuk koordinasi darat-darat serta memonitor kapal-kapal nelayan di laut (posisi kapal, keselamatan kapal).

\section{Very High Frequency Tranceiver}

Dengan jarak jangkau 100 meter, nahkoda kapal patroli biasanya menggunakan VHF tranceiver pada channel 5 dan 6 untuk berkomunikasi dengan kapal mitra (kapal pengangkut). Komunikasi juga dapat dilakukan pada channe/ 8 dan 16 namun karena sangat umum digunakan sehingga informasi yang diperoleh kurang jelas. Kapal-kapal nelayan juga menggunakan perangkat ini untuk komunikasi ke penampung ikan. Namun, perangkat ini rentan terhadap interferensi frekuensi sehingga sering terjadi doubling.

\section{Global Positioning System}

Nahkoda kapal patroli dari kantor syahbandar menggunakan GPS untuk memantau posisi kapal dan kondisi cuaca. GPS yang terintegrasi dengan radar digunakan sebagai perangkat navigasi untuk mengetahui posisi ikan.

\section{Radio Pantai}

Radio pantai merupakan salah satu media komunikasi milik Kementerian Perhubungan. Fungsi utama adalah sebagai sarana koordinasi dan mediator distribusi informasi, khususnya terkait dengan aktivitas keberangkatan dan kedatangan kapal. Radio pantai digunakan untuk komunikasi dengan petugas syahbandar. Radio pantai ini memiliki transmitter dan receiver di letakkan terpisah karena daya yag digunakan besar yaitu $1 \mathrm{KW}$ sehingga rentan terhadap interferensi. Transmitter menggunakan sistem komunikasi duplex pada band frekuensi HF. Biasanya menggunakan pasangan frekuensi 6510 dan 6215. Selain kedua frekuensi tersebut, radio pantai juga biasanya beroperasi di 9910, 8121, 8806, dan 8282. Perpindahan ke frekuensi yang lebih tinggi dimaksudkan untuk memperoleh kualitas suara yang lebih jelas. Transmitter terhubung dengan radio pantai lain dan menara suar. Adanya kerjasama dengan Badan Meteorologi, Klimatologi, dan Geofisika (BMKG) membantu stasiun radio pantai untuk memperoleh informasi cuaca yang dapat didistribusikan ke kapal-kapal nelayan tetapi stasiun radio ini tidak dapat memantau posisi kapal. Adapun perangkat receiver biasanya juga menggunakan Ultra High Frequency (UHF) untuk berkomunikasi dengan radio kecil. Diterbitkannya peraturan yang membebaskan pendirian stasiun radio pantai mengakibatkan jumlah kapal-kapal nelayan yang melapor melalui stasiun radio pantai pemerintah semakin menurun.

Saat ini masih banyak kapal nelayan atau yang dikenal dengan pelayaran rakyat yang tidak menggunakan komunikasi minimal sesuai dgn standarat Internasional ITU (International Telecommunication Union) Radio Regulation Tahun 2012 Artikel 31 dan Appedix 15 menyatakan bahwa setiap kapal harus memiliki GMDSS (Global maritime Distress and Safety System), yaitu perangkat yang memiliki (ITU Radio Regulation, 2012): 
1. Emergency position-indicating radio beacon (EPIRB). Berlokasi pada frekwensi 406 $\mathrm{MHz}$, alat ini terhubung dengan satelit SAR Cospas-Sarsat yang dikembangkan oleh Kanada, Prancis, AS dan Rusia.

2. Navtex, alat untuk menyebarluaskan informasi pelayaran, ramalan cuaca dan lainnya. Berbentuk printer dan dipasang di ruang kendali/anjungan, alat ini mencetak secara otomatis seluruh informasi cuaca, informasi pelayaran dan lainlain untuk kepentingan nahkoda atau awak kapal.

3. Sistem satelit Inmarsat yang terdiri dari Inmarsat A, B, C and F77.

4. Radio telepon dan radio teleks berfrekwensi tinggi.

5. Search and rescue transponder (SART) yang berfungsi melokalisasi kapal yang sedang berada dalam keadaan darurat.

6. Digital selective calling (DSC) adalah system pengiriman berita berbentuk text yang digunakan untuk mengirim berita secara otomatis dengan menggunakan system radio VHF-FM Marine Band dan High Frequency (HF). Teknik pengolahan digital pada system DSC dikombinasikan dengan penggunaan bandwidth receiver yang sempit, menghasilkan sinyal DSC yang relative bebas dari noise.Berada pada frekwensi MF, HF dan VHF, fungsi utamanya mengenali panggilan dari kapal ke kapal, kapal-ke-pantai dan pantai-ke-kapal.Kapal yang memasang alat ini biasanya dikenali dengan 9 digit angka maritime mobile service identity.DSC diperkenalkan kepada dunia pelayaran agar dalam keadaan darurat seorang awak kapal tidak perlu terpaku di depan pesawat radionya dalam menangani keadaan.

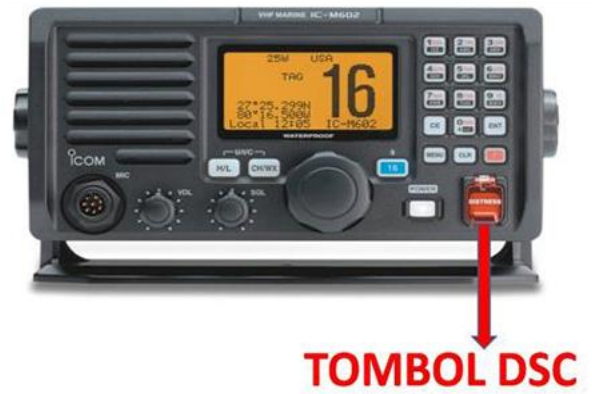

Gambar 3. Alat Komunikasi DSC (ITU Regulation, 2012)

Gambar 3 di atas adalah tombol DSC pada radio ICOM M602 VHF-FM Marine Band. Untuk pengoperasiannya sendiri sistem DSC digunakan untuk komunikasi kapal ke kapal, kapal ke darat maupun sebaliknya.Sistem DSC mengirimkan berbagai macam informasi, seperti :

Prioritas panggilan (Distress, Urgency, Safety atau Routine), Nomor MMSI (Maritime Mobile Service Identity), Posisi kapal, dan lain-lain. Frekuensi radio yang digunakan Sistem DSC, channel 70 pada VHF-FM Marine Band dan channe/2187.5 kHz pada MF/HF.

Peralatan GMDSS diatas memiliki harga yang sangat mahal, sehingga sangat menyulitkan nelayan membeli perangkat tersebut sehingga diperlukan suatu kajian penggunaan perangkat komunikasi yang lebih sederhana dan murah yang dapat dibeli oleh nelayan yang ada di Indonesia sehingga sesuai dengan aturan di Indonesia juga, yaitu : 
Undang-undang No. 9 Tahun 1985 Tentang Perikanan Pasal 4 mencantumkan keberadaan sistem komunikasi di kapal sebagai syarat penerbitan Surat Kelayakan Kapal Perikanan dengan kriteria sebagai berikut:

Kapal dengan ukuran <150 GT atau (<425 M3) harus dilengkapi dengan alat komunikasi radio yang siap digunakan dalam keadaan bahaya serta alat navigasi (Wahab, 2014).

\subsection{Identifikasi Frekuensi Saat Ini}

Berikut ini merupakan identifikasi frekuensi saat ini yang dapat dan layak digunakan sebagai frekuensi pelayaran rakyat berdasarkan aturan Internasional ITU Radio Regulation tahun 2012 dan Nasional Peraturan Menteri Komunikasi dan Informatika RI Nomor 25 Tahun 2014 Tentang Tabel Alokasi Spektrum Frekuensi Indonesia aturan mengenai pelayaran rakyat, antara lain :

1. Frekuensi $159.05 \mathrm{MHz}$ dan $159.075 \mathrm{MHz}$

\begin{tabular}{|c|l|l|}
\hline Frekuensi Radio & \multicolumn{1}{|c|}{ Wilayah 3-ITU } & \multicolumn{1}{c|}{ Alokasi Indonesia } \\
\hline $156,8375-161,9625$ & TETAP & TETAP \\
& BERGERAK & BERGERAK \\
& 5.226 & 5.226 \\
\hline
\end{tabular}

Gambar 4. Alokasi Frekuensi Indonesia Frekuensi 156,8375-161,9625 Mhz (Sumber : Peraturan Menteri Kominfo RI Nomor 25 Tahun 2014 Tentang Tabel Alokasi Spektrum Frekuensi Indonesia)

Frekuensi 159.05 dan $159.075 \mathrm{MHz}$ berada pada rentang frekuensi 156.8375 - 161.9625 MHz (Gambar 4) yang peruntukkannya menurut ITU Radio Regulation 2012 dan Peraturan Menteri Komunikasi dan Informatika RI Nomor 25 Tahun 2014 Tentang Tabel Alokasi Spektrum Frekuensi Indonesia adalah Tetap Bergerak, juga di dalam Artikel 5.226 dinyatakan bahwa : diperuntukkan dinas radiokomunikasi VHF bergerak maritim, sehingga dapat digunakan sebagai frekuensi Pelayaran rakyat untuk komunikasi.

2. Frekuensi $172-173 \mathrm{MHz}$

Frekuensi 172 - $173 \mathrm{MHz}$ merupakan frekuensi yang pernah digunakan oleh alat komunikasi pager.

\begin{tabular}{|l|l|l|}
\hline Frekuensi Radio & \multicolumn{1}{|c|}{ Wilayah 3-ITU } & \multicolumn{1}{c|}{ Alokasi Indonesia } \\
\hline \hline $162,0375-174$ & TETAP & TETAP \\
& BERGERAK & BERGERAK \\
& 5.2265 .2305 .2315 .232 & $5.226 \quad 5.230 \quad 5.231 \quad 5.232$ \\
\hline
\end{tabular}

Gambar 5. Alokasi Frekuensi Indonesia Frekuensi 162.0375 - 174 Mhz (Sumber : Peraturan Menteri Kominfo RI Nomor 25 Tahun 2014 Tentang Tabel Alokasi Spektrum Frekuensi Indonesia)

Frekuensi 172-173 MHz berada pada range frekuensi 162.0375 - $174 \mathrm{MHz}$ (Gambar 5) yang peruntukkannya menurut ITU Radio Regulation 2012 dan Peraturan Menteri Komunikasi dan Informatika RI Nomor 25 Tahun 2014 Tentang Tabel Alokasi Spektrum Frekuensi Indonesia 
adalah Tetap Bergerak, juga di dalam Artikel 5.226 dinyatakan bahwa : diperuntukkan dinas radiokomunikasi VHF bergerak maritim, sehingga dapat digunakan sebagai frekuensi Pelayaran rakyat untuk komunikasi.

3. Frekuensi $2170-2173.5 \mathrm{kHz}$

\begin{tabular}{|c|c|c|}
\hline Frekuensi Radio & Wilayah 3-ITU & Alokasi Indonesia \\
\hline $2170-2173,5$ & BERGERAK MARTTIM & BERGERAK MARITIM \\
\hline
\end{tabular}

Gambar 6. Alokasi Frekuensi Indonesia Frekuensi 2170 - $2173.5 \mathrm{KHz}$ (Sumber : Peraturan Menteri Kominfo RI Nomor 25 Tahun 2014 Tentang Tabel Alokasi Spektrum Frekuensi Indonesia)

Pada alokasi frekuensi 2170 - $2173.5 \mathrm{KHz}$ (Gambar 6), semua layanan bergerak maritim dapat dilakukan, misalnya: radiotelephony, radiotelegraphy, radio buoy, komunikasi kerja, pelayaran rakyat, sehingga dapat digunakan sebagai frekuensi Pelayaran rakyat untuk komunikasi.

4. Frekuensi $2190.5-2194 \mathrm{kHz}$

\begin{tabular}{|c|c|c|}
\hline Frekuensi Radio & Wilayah 3-ITU & Alokasi Indonesia \\
\hline $2190,5-2194$ & BERGERAK MARITIM & BERGERAK MARITIM \\
\hline
\end{tabular}

Gambar 7. Alokasi Frekuensi Indonesia Frekuensi 2190.5 - 2194 KHz (Sumber : Peraturan Menteri Kominfo RI Nomor 25 Tahun 2014 Tentang Tabel Alokasi Spektrum Frekuensi Indonesia)

Pada alokasi frekuensi 2190.5 - $2194 \mathrm{KHz}$ (Gambar 7), semua layanan bergerak maritim dapat dilakukan, misalnya: radiotelephony, radiotelegraphy, radio buoy, komunikasi kerja, pelayaran rakyat, sehingga dapat digunakan sebagai frekuensi Pelayaran rakyat untuk komunikasi.

5. Frekuensi $8100-8195 \mathrm{kHz}$

\begin{tabular}{|l|l|l|}
\hline \multicolumn{1}{|c|}{ Frekuensi Radio } & \multicolumn{1}{|c|}{ Wilayah 3-ITU } & \multicolumn{1}{c|}{ Alokasi Indonesia } \\
\hline \hline $8100-8195$ & TETAP & TETAP \\
& BERGERAK MARITIM & BERGERAK MARITIM \\
\hline
\end{tabular}

\section{Gambar 8. Alokasi Frekuensi Indonesia Frekuensi 8100 - 8195 KHz (Sumber : Peraturan Menteri Kominfo RI Nomor 25 Tahun 2014 Tentang Tabel Alokasi Spektrum Frekuensi Indonesia)}

Pada alokasi frekuensi 8100 - $8195 \mathrm{KHz}$ (Gambar 8), semua layanan bergerak maritim memungkinkan dilakukan, misalnya: radiotelephony, radiotelegraphy, radio buoy, komunikasi kerja, pelayaran rakyat, sehingga dapat digunakan sebagai frekuensi Pelayaran rakyat untuk komunikasi. 
6. Frekuensi $18780-18900 \mathrm{kHz}$

\begin{tabular}{|l|l|l|l|}
\hline \multicolumn{2}{|c|}{ Frekuensi Radio } & \multicolumn{1}{c|}{ Wilayah 3-ITU } & \multicolumn{1}{c|}{ Alokasi Indonesia } \\
\hline $18780-18900$ & BERGERAK MARTTIM & BERGERAK MARITIM \\
\hline
\end{tabular}

Gambar 9. Alokasi Frekuensi Indonesia Frekuensi 18780 - 18900 KHz (Sumber : Peraturan Menteri Kominfo RI Nomor 25 Tahun 2014 Tentang Tabel Alokasi Spektrum Frekuensi Indonesia)

Pada alokasi frekuensi 18780 - $18900 \mathrm{KHz}$ (Gambar 9), semua layanan bergerak maritim memungkinkan dilakukan, misalnya: radiotelephony, radiotelegraphy, radio buoy, komunikasi kerja, pelayaran rakyat, sehingga dapat digunakan sebagai frekuensi Pelayaran rakyat untuk komunikasi.

7. Frekuensi $25070-25210 \mathrm{kHz}$

\begin{tabular}{|c|l|l|l|}
\hline \multicolumn{2}{|c|}{ Frekuensi Radio } & \multicolumn{1}{|c|}{ Wilayah 3-ITU } & Alokasi Indonesia \\
\hline \hline $25070-25210$ & BERGERAK MARITIM & BERGERAK MARITIM \\
\hline
\end{tabular}

Gambar 10. Alokasi Frekuensi Indonesia Frekuensi 25070 - 25210 KHz (Sumber : Peraturan Menteri Kominfo RI Nomor 25 Tahun 2014 Tentang Tabel Alokasi Spektrum Frekuensi Indonesia)

Pada alokasi frekuensi 25070 - $25210 \mathrm{KHz}$ (Gambar 10), semua layanan bergerak maritim memungkinkan dilakukan, misalnya: radiotelephony, radiotelegraphy, radio buoy, komunikasi kerja, pelayaran rakyat, dan lainnya sehingga dapat digunakan sebagai frekuensi Pelayaran rakyat untuk komunikasi.

\subsection{Benchmark (Studi Banding) Negara Lainnya}

Berikut ini merupakan benchmark atau studi banding literatur penerapan penggunaan frekuensi khusus untuk pelayaran rakyat di negara lain, antara lain adalah :

1. United Emirat Arab (Telecommunication Regulation Authority) Menyatakan bahwa kapal nelayan atau pelayaran rakyat yang lebih kecil dari 300 GT di kategorikan sebagai kapal kecil untuk memancing hanya memerlukan 1 set radio komunikasi VHF dengan frekuensi 157.425 MHz simplex (kanal 88) dan frekuensi $156.80 \mathrm{MHz}$ (Kanal 16) untuk gawat darurat (Emergency calls) dan untuk panggilan Distress saja (Telecommunications Regulatory Authority United Arab Emirates).

2. Negara New Zealand

Untuk kapal yang lebih kecil dari 300 GT dan tidak melewati garis pantai, maka pemerintah New Zealand tidak mewajibkan nelayan ini menggunakan radio GMDSS (Maritime New Zealand, "Maritime Rules Part 43"). 


\section{KESIMPULAN}

Berdasarkan hasil studi literatur, studi banding dan frekuensi eksisting di Indonesia dapat disimpulkan dan di rekomendasikan beberapa hal sebagai berikut:

1. Untuk komunikasi antar nelayan dari satu kapal ke kapal lainnya menggunakan frekuensi VHF (Very High Frequency) 30 - $300 \mathrm{MHz}$ dengan pertimbangan jarak jangkauan.

2. Di Indonesia dan beberapa negara untuk kapall di bawah 300 GT diberi frekuensi khusus termasuk kapal nelayan yang termasuk ke dalam kategori pelayaran rakyat di Indonesia.

3. Frekuensi yang di mungkinkan untuk digunakan oleh pelayaran rakyat adalah 2170$2173,5 \mathrm{KHz}, 2190-2194 \mathrm{KHz}, 8100-8195 \mathrm{KHz}, 18780-18900 \mathrm{KHz}, 25070-25210 \mathrm{KHz}$, 159.05 MHz, $159.075 \mathrm{MHz}$ dan 172-173 MHz.

4. Hasil studi banding dengan negara lain seperti United Emirat Arab menggunakan frekuensi $156.80 \mathrm{Mhz}$ (kanal 16) untuk gawat darurat dan radio komunikasi menggunakan frekuensi $157.425 \mathrm{MHz}$ Simplex (kanal 88), sedangkan negara Jepang mulai tahun 1988 menggunakan frekuensi $400 \mathrm{MHz}$.

\section{DAFTAR RUJUKAN}

Wahab, R., A.. (2014). Penggunaan Alat dan Perangkat Telekomunikasi dalam Sistem Navigasi dan Komunikasi Aktivitas Perikanan di Pelabuhan Perikanan Bitug. Buletin Pos dan Telekomunikasi. 12(4) : 279-290.

Yudhariksawan (2005). Pengantar Hukum Telekomunikasi. Jakarta : Radjawali Pers.

Susilowati, E. (2013). Dari Pelabuhan Martapura ke Pelabuhan Trisakti : Pelayaran Perahu Rakyat Di antara Derap Modernisasi, 1965 - 1995. Jurnal Sejarah CITRA LEKHA. 17(1) :19-32.

Dhika, D., Affandi, A., Setijadi, E. (2011). Rancang Bangun Antena pada Frekuensi HF sebagai Base station untuk komunikasi di Laut. Surabaya : Institut Teknologi Sepuluh November (ITS).

Undang-undang Republik Indonesia No. 9 Tahun 1985 Tentang Perikanan.

Peraturan Menteri Perhubungan Nomor PM 26 Tahun 2011 Tentang Telekomunikasi Pelayaran.

Peraturan Pemerintah Republik Indonesia Nomor 20 Tahun 2010 Tentang Angkutan di Perairan.

International Telecommunication Union (ITU) Radio Regulation Tahun 2012.

Peraturan Menteri Komunikasi dan Informatika RI Nomor 25 Tahun 2014 Tentang Tabel Alokasi Spektrum Frekuensi Indonesia.

Telecommunications Regulatory Authority United Arab Emirates Maritim Radio Service Version 1.0.

Maritime Rules New Zealand Part 43 Tahun 2015. 